Int. J. Electrochem. Sci., 14 (2019) 8080 - 8096

\title{
Corrosion Inhibition Effect of Tungstate on Fine-Grain High- Strength Reinforcement in Simulated Concrete Pore Solutions Containing Chloride Ions
}

\author{
Bilan $\operatorname{Lin}^{1,2, *}$ Xiaojuan $\mathrm{Liu}^{1}$ and Yuye $\mathrm{Xu}^{3, *}$ \\ ${ }^{1}$ School of Material Science and Engineering, Xiamen University of Technology, Xiamen, 361024 \\ Fujian, China \\ ${ }^{2}$ Key Laboratory of Functional Materials and Applications of Fujian Province, Xiamen, 361024 \\ Fujian, China \\ ${ }^{3}$ College of Civil Engineering, Huaqiao University, Xiamen, 361021 Fujian, China \\ *E-mail: linbilan@xmut.edu.cn; yuyexu@hqu.edu.cn
}

doi: $10.20964 / 2019.08 .88$

Received: 28 November 2018 / Accepted: 9 February 2019 / Published: 30 June 2019

Tungstate and tungstate/tartrate inhibitors were used to mitigate the corrosion of fine-grain highstrength (FGHS) reinforcement in simulated concrete pore solutions containing $3.5 \% \mathrm{NaCl}$. The physical laws governing the inhibition were investigated using potentiodynamic polarization and electrochemical impedance spectroscopy. The semiconductor characteristics of the corrosion products were analyzed by plotting the Mott-Schottky curves and the corrosion morphology was observed using SEM. A comparison with conventional carbon steel reinforcement (HPB300 steel) was also performed. The results indicated that tungstate is an anodic corrosion inhibitor. Sodium tungstate at concentrations between 0.1 and $0.3 \mathrm{~g} / \mathrm{L}$ provided good corrosion inhibition, decreasing the corrosion current density from $12.3 \mu \mathrm{A} \cdot \mathrm{cm}^{-2}$ to $0.326 \mu \mathrm{A} \cdot \mathrm{cm}^{-2}$. The carrier density of the corrosion product layer and the electric double-layer capacitance decreased dramatically, while the charge transfer resistance improved significantly. Furthermore, only a few pits formed on the FGHS reinforcement. The tungstate/tartrate mixed inhibitor was found to display the advantages of a single inhibitor, although no synergistic effect was observed. When the inhibitor was absent, the corrosion resistance properties of FGHS reinforcement were clearly inferior to those of HPB300 steel. However, the addition of tungstate or tungstate/tartrate mixed inhibitor led to improved indicators of corrosion resistance for the FGHS sample relative to HPB300 steel.

Keywords: Reinforcement; Corrosion; Inhibitor; Tungstate; Electrochemical corrosion FULL TEXT 
(C) 2019 The Authors. Published by ESG (www.electrochemsci.org). This article is an open access article distributed under the terms and conditions of the Creative Commons Attribution license (http://creativecommons.org/licenses/by/4.0/). 